\title{
Physical Properties of Medium Density Fiberboard Produced with the Addition of ZnO Nanoparticles
}

\author{
Ana Paula Santos da Silva, ${ }^{\mathrm{a}, *}$ Bruno Santos Ferreira, ${ }^{\mathrm{b}}$ Higor Rogério Favarim, ${ }^{\mathrm{b}}$ \\ Maria Fernanda Felippe Silva, ${ }^{\mathrm{b}}$ João Vítor Felippe Silva, ${ }^{\mathrm{a}}$ \\ Maximiliano dos Anjos Azambuja, ${ }^{c}$ and Cristiane Inácio de Campos ${ }^{b}$
}

\begin{abstract}
The use of wood-base panels in humid environments, in general, presents low durability due to contact with water. In order to increase durability and reduce the attack of fungi, studies had been developed using resin with zinc oxide $(\mathrm{ZnO})$ nanoparticles. This work aimed to produce medium density fiberboard with urea-formaldehyde resin and melamineformaldehyde adding $0.5 \%$ and $1.0 \%$ of $\mathrm{ZnO}$ nanoparticles for the physical properties evaluation. All treatments were classified as medium density according to ABNT NBR 15.316-2 (2015) with values ranging between 550 and $800 \mathrm{~kg}^{*} \mathrm{~m}^{-3}$. No differences were found between the two commercial adhesives used. The addition of $1.0 \%$ of nanoparticles resulted in lower density panels, higher moisture contents, and, after immersion in water for 24 hours, higher values of swelling in thickness. These results are explained by the lower compaction of the boards due to rapid cure of the adhesive using higher percentages of $\mathrm{ZnO}$ nanoparticles. The best treatment of the panels was with melamine-formaldehyde resin and $0.5 \%$ of nanoparticles.
\end{abstract}

Keywords: Fiberboard; Physical characteristics; Nanotechnology

Contact information: a: Department of Mechanical Engineering, São Paulo State University (UNESP), Avenida Ariberto Pereira da Cunha, 333, Guaratinguetá/SP, Brazil; b: São Paulo State University (UNESP), Campus of Itapeva, Rua Geraldo Alckmin, 519, Itapeva/SP, Brazil; c: Department of Civil Engineering, São Paulo State University (UNESP), Avenida Engenheiro Edmundo Carrijo Coube, 14-01, Bauru/SP, Brazil;

* Corresponding author: Ana Paula Santos da Silva (ana.paulal@outlook.com)

\section{INTRODUCTION}

Wood panels have a great number of applications in the civil construction and the furniture industry, especially particulate and fiber panels. The production of medium density fiberboard (MDF) panels is carried out by a continuous hot-pressing process with the addition of adhesives. The adhesives employed by the industry are urea-formaldehyde and melamine-formaldehyde. Dimensional changes may occur, decreasing the mechanical strength of MDF panels when exposed to more aggressive conditions. To lessen the possible negative effects on the panels, other materials can be added during the manufacturing process in addition to the products already used. New studies have the objective of improving properties of the panels in terms of physical and mechanical performance and durability of the product.

In this context, nanoparticles are an example of materials that show good results, such as a decrease of swelling and lower mass gain when in contact with water. Research on the synthesis of nanomaterials is mainly focused on controlling their shapes, sizes, and compositions. Each of these factors is key in determining the properties of the materials and lead to different technological applications (Ghorbani et al. 2017). 
Weichelt et al. (2010) developed nanocomposites for use in ultraviolet resistant coatings using zinc oxide nanoparticles in wood panels for outdoor use. The suitability of these panels for use under outdoor conditions was ensured by increasing the elasticity of the coatings and decreasing the water permeability of the panels.

The use of $\mathrm{ZnO}$ nanoparticles on wood-based panels has shown good performance against fungal attack (Reinprecht et al. 2018); however, it should not impair the physical and mechanical properties of the boards. So, it may be possible to add a nanomaterial that allows better performance of the panels especially in humid environments, such as kitchens and bathrooms.

Gupta et al. (2018) evaluated the application of high conductivity nanoparticles for improving the thermal and mechanical properties of MDF as well as using a ureaformaldehyde resin in their composition. The authors added multi-walled carbon nanotubes (CNTs), aluminum oxide $\left(\mathrm{Al}_{2} \mathrm{O}_{3}\right)$ nanoparticles, and activated carbon nanoparticles to the adhesive. Activated carbon and $\mathrm{Al}_{2} \mathrm{O}_{3}$ nanoparticles increase the amount of heat transfer during the pressing process, improving the physico-mechanical properties of the MDF. In addition, activated carbon nanoparticles significantly reduce formaldehyde emissions from the panel production process.

Kumar et al. (2013) evaluated the effects of $\mathrm{Al}_{2} \mathrm{O}_{3}$ nanoparticles on the physical, mechanical, and heat transfer properties of MDF. The nanoparticles were added at two levels, $0.5 \mathrm{wt} . \%$ and $1.0 \mathrm{wt} . \%$ of the dry weight of wood fibers. The resin used was ureaformaldehyde. The temperature profile inside the panel and the thermal conductivity were improved by the addition of $\mathrm{Al}_{2} \mathrm{O}_{3}$ nanoparticles, subsequently improving the adhesion of the fibers in the MDF. The modulus of rupture and the modulus of elasticity also showed improvement over the control panels and the thickness swelling decreased.

Furthermore, nanoparticles can be applied on the surface of boards. Nosál and Reinprecht (2017) applied zinc oxide ( $\mathrm{ZnO}$ ) nanoparticles to the surface layer of medium density particleboard (MDP) to improve their anti-bacterial and anti-mold properties. Melamine-formaldehyde resin and $\mathrm{ZnO}$ nanoparticles, in the amounts of $0.1 \%, 0.3 \%$, $0.6 \%$, and $1.0 \%$, were used for the impregnation of white decorative paper in MDP panels. The presence of $\mathrm{ZnO}$ increased the surface mold resistance of panels intentionally contaminated with microscopic fungi by approximately $50 \%$.

Soltani et al. (2013) studied the effect of four different concentrations of zinc oxide nanoparticles used in the treatment of beech wood by the submersion method in order to evaluate the dimensional stability and swelling for 24 hours. Beech wood was thermally treated at 60 and $120^{\circ} \mathrm{C}$ after impregnation of nanoparticles. The results indicated that the nanoparticles of $\mathrm{ZnO}$ provided modification in the wood, improving the dimensional stability and reducing its hygroscopicity. In addition, Fourier Transform Infrared Spectroscopy (FTIR) analysis indicated a strong interaction between the nanoparticles and the chemical components of the wood. Thermal treatment effectively improved the effects of nanoparticles.

One of the great challenges of adding nanoparticles to wood panels is finding the optimum percentage of application for improving the physical and heat transfer properties of the product without adversely affecting its mechanical properties.

Taghiyari (2013) determined the effects of the addition of silver nanoparticles and zycosil nanoparticles on the mechanical resistance of MDF. The study concluded that nanoparticles did not positively influence the mechanical strength of the panels.

Gao et al. (2011) presented the effects of copper oxide nanoparticles on the physical and mechanical properties of oriented strandboard (OSB) using phenol formaldehyde (FF) 
resin. The copper oxide nanoparticles had no beneficial effects on the mechanical properties and dimensional stability of OSB panels. However, the addition of nanoparticles did result in the acceleration of FF resin reactions and in an increase of heat transfer in the wood strands mattress.

Reinprecht et al. (2018) studied the addition of four different percentages (2, 6, 12 and $24 \%$, by weight) of $\mathrm{ZnO}$ nanoparticles in wood particulate panels produced with MUF resin. The use of nanoparticles improved the resistance of the boards against biological agents; however, there were no major changes for the different percentages tested. The presence of zinc oxide nanoparticles in the particulate panels decreased its internal bonding and did not influence swelling in thickness and water absorption after 2 and $24 \mathrm{~h}$ and resistance in static bending.

The present work evaluated the physical performance of MDF panels produced with eucalyptus fibers, the addition of zinc oxide nanoparticles in proportions of $0.5 \%$ and $1 \%$ based on fiber dry weight, and urea formaldehyde and melamine-formaldehyde resins.

\section{EXPERIMENTAL}

The fibers used for the production of MDF panels were wood fibers of Eucalyptus grandis hybrid H103 donated by a timber company (Eucatex, Salto, Brazil). The adhesives used, urea-formaldehyde (UF) with the solids content of $66 \%$ and melamine-formaldehyde (MF) with the solids content of 65.9\%, were donated by Momentive Indústria Química. The catalyst contained the following: ammonium sulfate with the solids content of $13.10 \%$, emulsion of paraffin with the solids content of 57.2\% (provided by Eucatex), water, and $\mathrm{ZnO}$ nanoparticles obtained from the sol-gel method from the synthesis of zinc nitrate and gelatin in the ratio of 1:1 (Favarim and Leite 2018).

The work was carried out over a total of six treatments, which were divided between panels produced with the UF and MF adhesives. Table 1 shows the nomenclature of the treatments, the type of adhesive used, and the percentage of nanoparticles used for each treatment. The proportion of materials and the production process of the panels are described below.

Table 1. Characteristics of the Treatments

\begin{tabular}{|c|c|c|}
\hline Treatments & Adhesive & ZnO Nanoparticles (\%) \\
\hline T1 & UF & 0 \\
\hline T2 & UF & 0.5 \\
\hline T3 & UF & 1 \\
\hline T4 & MF & 0 \\
\hline T5 & MF & 0.5 \\
\hline T6 & MF & 1 \\
\hline
\end{tabular}

\section{MDF Panels Production}

Before panel production, the fibers were oven dried to a moisture content of $3 \mathrm{wt} . \%$. For each panel, $1800 \mathrm{~g}$ of fibers were mixed with adhesive in a laboratory blender. A fiber mat was formed, and the material was cold pre-pressed via a manual process with a pressure of approximately $1 \mathrm{kgf} / \mathrm{cm}^{2}$ for $5 \mathrm{~min}$ to reduce the volume of the fiber mat. Hot pressing with a pressure of $10 \mathrm{kgf} / \mathrm{cm}^{2}$ and a temperature of $180{ }^{\circ} \mathrm{C}$ was carried out for $10 \mathrm{~min}$, resulting in an MDF panel with a final thickness of approximately $13 \mathrm{~mm}$. This process 
was divided into three cycles of 3 min of hot-pressing with a 30-s break, according to Campos and Lahr (2004) method.

\section{Tests and Results Analysis}

The physical tests conducted included the determination of density, moisture content, and thickness swelling after a 24-h water immersion. Preparation of the specimens and the procedures for each test were developed according to the normative document ABNT NBR 15316-2 (2015). A semi analytical scale (0.01 g of precision), a digital caliper ( $0.01 \mathrm{~mm}$ of precision), and a micrometer $(0.001 \mathrm{~mm}$ of precision) were used to perform the physical tests

\section{Determination of apparent density}

Density for each treatment was determined using ten square specimens of $50 \mathrm{~mm}$ side (see Eq. (1)). Width and length were measured with a caliper, thickness was measured in five different points - four corners and at the center - with a micrometer and mass was determined with a precision scale,

$$
D=[m /(w / t)]^{*} 1,000,000
$$

where $D$ is the apparent density $\left[\mathrm{kg} * \mathrm{~m}^{-3}\right] ; m$ is the mass of the specimen $[\mathrm{g}] ; w$ is the width [mm]; $l$ is the length [mm]; and $t$ is the thickness $[\mathrm{mm}]$.

\section{Determination of moisture content}

Each treatment moisture content (see Eq. (2)) was determined using ten square specimens of $50 \mathrm{~mm}$ side with initial mass determined in a precision scale. Samples were dried in a laboratory oven at $103 \pm 2{ }^{\circ} \mathrm{C}$ until reaching constant mass (i.e. fluctuation between mass measurements inferior of $0.1 \%$ ),

$$
U=\left[\left(m_{i}-m_{d}\right) / m_{i}\right]^{*} 100
$$

where $U$ is the moisture content [\%]; $m_{i}$ is the initial mass of the specimen [g]; and $m_{d}$ is the dried mass of the specimen $[\mathrm{g}]$.

\section{Determination of thickness swelling}

Ten square specimens with dimensions of $50 \mathrm{~mm}$ x $50 \mathrm{~mm}$ were completely submerged in water in order to determine treatments thickness swelling (see Eq. (3)). Thickness swelling was determined by the increase in the thickness dimension after the specimens were soaked in water for 24 hours, measured by a micrometer with precision of $0.001 \mathrm{~mm}$. Water had a constant temperature of $25^{\circ} \mathrm{C}$ and $\mathrm{pH}$ of 7 during the test,

$$
T S=\left[\left(t_{s}-t_{i}\right) / t_{i}\right] * 100
$$

where $T S$ is the thickness swelling [\%]; $t_{s}$ is the specimen thickness after water soaking $[\mathrm{mm}]$; and $t_{i}$ is the specimen initial thickness [mm].

The results of the physical tests were analyzed with analysis of variance and Tukey tests with significance levels of 5\% using $R$ software version 3.3.1 (https://www.Rproject.org/). 


\section{RESULTS AND DISCUSSION}

Table 2 presents the average results obtained for the physical tests of density, moisture content, and 24-h thickness swelling for all the treatments studied. The panels from treatments 1, 2, 4, and 5 presented density values in accordance with ABNT NBR $15316-2$ (2015), which indicates the range of density from $651 \mathrm{~kg} / \mathrm{m}^{3}$ to $800 \mathrm{~kg} / \mathrm{m}^{3}$ for panels with thickness between $12 \mathrm{~mm}$ to $19 \mathrm{~mm}$. Treatments 3 and 6 met the requirements of the ANSI A2008.2 (2016) standard.

According to ANSI A2008.2 (2016) medium density boards have values ranging from 500 to $1000 \mathrm{~kg}^{*} \mathrm{~m}^{-3}$ for interior applications, so the panels of the T3 and T6 treatments fit into this group.

Table 2. Average Density, Moisture Content, and 24-h Thickness Swelling

\begin{tabular}{|c|c|c|c|c|c|}
\hline Treatment & Condition & Density $\left(\mathrm{kg} / \mathrm{m}^{3}\right)$ & $\begin{array}{c}\text { Moisture } \\
\text { Content (\%) }\end{array}$ & $\begin{array}{c}\text { 24-h Thickness } \\
\text { Swelling (\%) }\end{array}$ & $\begin{array}{c}\text { 24-h Thickness } \\
\text { Swelling }(\mathrm{mm})\end{array}$ \\
\hline T1 & UF & $749.75 c^{2}(30.88)^{1}$ & 5.54 b (0.20) & 18.46 b (2.38) & $2.40(0.41)$ \\
\hline T2 & $0.5 \% \mathrm{ZnO}+\mathrm{UF}$ & 689.11 b (63.82) & 5.56 b (0.21) & $15.26 \mathrm{ab}(2.41)$ & $2.22(0.67)$ \\
\hline T3 & $1.0 \% \mathrm{ZnO}+\mathrm{UF}$ & 588.49 a (36.03) & 7.29 c (0.19) & 36.70 c (2.91) & $5.11(0.38)$ \\
\hline $\mathrm{T} 4$ & MF & 779.67 c (35.65) & $4.77 \mathbf{a b}(1.22)$ & 17.17 b (1.10) & $1.99(0.29)$ \\
\hline T5 & $0.5 \% \mathrm{ZnO}+\mathrm{MF}$ & 748.43 c (61.58) & $4.04 \mathbf{a}(1.13)$ & 11.77 a (2.75) & $1.55(0.39)$ \\
\hline T6 & $1.0 \% \mathrm{ZnO}+\mathrm{MF}$ & 588.96 a (24.04) & 7.33 c $(0.10)$ & 36.93 c (2.30) & $5.21(0,36)$ \\
\hline
\end{tabular}

The moisture contents obtained from all treatments were more homogeneous than the density, even with the addition of nanoparticles. Treatments 1 and 2 (panels produced with UF) presented very similar moisture contents, with values of $5.54 \%$ and $5.56 \%$, respectively. For treatments 4 and 5 (panels produced with MF), the values of moisture content were lower: $4.77 \%$ and $4.04 \%$, respectively. The superior performance of the panels produced with MF occurred due to their greater resistance to water.

Treatments 3 and 6 (1\% addition of nanoparticles in panels produced with UF and MF, respectively) presented higher values of moisture content, namely $7.29 \%$ and $7.33 \%$, respectively. The addition of nanoparticles accelerated the curing of the resin in the outermost regions of the mats and limited the heat transfer to the innermost regions, making it difficult for water vapor to escape, which may have caused an increase in the moisture content of the panel. The normative document used does not present reference values for this test.

The maximum 24-h thickness swelling value allowed by ABNT NBR 15316-2 (2015) is $12 \%$ for panels with nominal thicknesses between $12 \mathrm{~mm}$ and $19 \mathrm{~mm}$. Treatments 1,2 , and 4 obtained higher swelling values of $18.46 \%, 15.26 \%$, and $17.17 \%$, respectively. Treatment 5 presented a thickness swelling within the established limits (11.77\%). Notably, treatments 3 and 6 presented values much higher than the other treatments, which may indicate that the use of $1 \%$ of $\mathrm{ZnO}$ nanoparticles greatly accelerated the curing of the panels' outer layers and prevented uniform heat transfer over its thickness, impairing the performance of the panels in direct contact with water.

The standard ANSI A2008.2 (2016) states that the thickness difference before and after the test should be a maximum of $1.5 \mathrm{~mm}$ for panels with a thickness of less than or 
equal to $15 \mathrm{~mm}$. Treatments $1,2,4$, and 5 showed thickness variations of $2.4 \mathrm{~mm}, 1.9 \mathrm{~mm}$, $2.2 \mathrm{~mm}$, and $1.5 \mathrm{~mm}$, respectively. Thus, treatment 5 presented acceptable results according to the ANSI document in the same way that it did for the Brazilian standard. For treatments 3 and 6, the thickness variation was even higher: $2.91 \mathrm{~mm}$ and $2.30 \mathrm{~mm}$, respectively.

None of the treatments presented values in accordance with the established standards except for treatment 5; however, the addition of nanoparticles caused a remarkable decrease of swelling percentages, for both panels with $0.5 \% \mathrm{UF}$ and MF. The decreases observed were a $3.2 \%$ decrease of thickness between treatments 1 and 2 and a $5.4 \%$ decrease for treatments 4 and 5. Regarding the thickness of the panels from treatment 3 , the panels from treatment 2 showed a $21.44 \%$ increase of thickness. The panels from treatment 6 , with respect to those from treatment 5, presented a $25.16 \%$ increase in thickness.

Kumar et al. (2013) analyzed the possible changes in temperature inside MDF panels during pressing with the addition of aluminum oxide nanoparticles in a urea-formaldehyde resin. They compared the average 24-h thickness swelling results for panels without the addition of the nanoparticles with those from panels with $0.5 \%, 14.1 \%$, and $13.5 \%$. Their results also presented values higher than those mentioned in the normative documents, namely $12 \%$. Nanoparticles of aluminum oxide, zinc oxide, positively influenced the decrease of the percentage of swelling in this percentage, although the panels were still unable to meet the normative specifications.

Mantanis and Papadopoulos (2010) evaluated the 24-h thickness swelling of three types of commercial wood panels with and without a surface application of a nanoparticle solution called SurfaPore W, which, according to the manufacturer, decreases water absorption and impregnation of oil stains on wood. The authors stated that MDF panels treated with the product showed a $13.6 \%$ decrease in thickness swelling. There was a smaller increase in panel thickness in the study cited than there was in the results obtained, which were $14.1 \%$ and $18.2 \%$ for the treatments with UF and MF, respectively. The panels produced in this work showed a percentage of 24-h thickness swelling that was higher when compared to panels treated with the commercial product SurfaPore W, except for the panels from treatment 5, which presented a better performance. Obtaining the best results from the panels from treatment 5 can be justified by the combination of MF resin already presenting a better performance in contact with water and the favorable effect on the observed heat transfer with the addition of $\mathrm{ZnO}$ nanoparticles.

The lower densities observed from treatments 3 and 6 are directly related to the greater percentages of swelling in thickness. This can be explained by the lower compaction of the panels due to accelerated curing from using higher percentage of $\mathrm{ZnO}$ nanoparticles. This accelerated cure also had a direct relationship with the moisture content of the panels from these treatments that were superior and statistically different from the others.

A further study of the panels' density profiles would allow better analysis and conclusions on the performance of the addition of nanomaterials in panel fabrication.

Regarding the use of two different resins, the best results were obtained for the panels produced with MF resin because of their better mechanical performance and their higher water resistance. 


\section{CONCLUSIONS}

1. The addition of $0.5 \% \mathrm{ZnO}$ nanoparticles presented better results for the medium density fiberboard, confirming what previous studies had already shown - the ideal percentage of addition must be found, and it may not necessarily be the greatest one.

2. Regarding the 24-hour thickness swelling, it was observed that the addition of $0.5 \%$ of nanoparticles presented the best results, indicating improvement in the performance of the panels in contact with water. However, an addition of $1 \%$ nanoparticles compromised the results.

3. The addition of $1 \%$ of $\mathrm{ZnO}$ nanoparticles, used for both UF and MF panel production, indicated a reduction in panel density and an increase in moisture content. These may have occurred due to the acceleration of heat transfer over the hot-pressing, making it difficult to thicken the panel, especially in the inner layer.

\section{ACKNOWLEDGMENTS}

The authors are grateful for the support of the Coordination for the Improvement of Higher Education Personnel (CAPES) - Brazil.

\section{REFERENCES CITED}

ABNT NBR 15.316-2 (2015). "Painéis de fibras de média densidade-Parte 2: Requisitos e métodos de ensaio," Associação Brasileira de Normas Técnicas (ABNT), Rio de Janeiro, Brazil.

ANSI A2008.2 (2016). "Medium density fiberboard (MDF) for interior applications," American National Standards Institute, New York, USA.

Campos, C. I. de, and Lahr, F. A. R. (2004). "Production and characterization of MDF using eucalyptus fibers and castor oil-based polyurethane resin," Materials Research 7(3), 421-425. DOI: 10.1590/S1516-14392004000300008

Favarim, H. R. and Leite, L. O. (2018). "Performance of $\mathrm{ZnO}$ nanoparticles for fire retardant and UV protection of pine wood," BioResources 13(3), 6963-6969. DOI: 10.15376/biores.13.3.6963-6969

Gao, W., Cao, J., and Kamdem, D. P. (2011). "Effect and mechanism of nanosize copper oxide on some physical and mechanical properties of flakeboards," Maderas Ciencia y Tecnología 13(2), 203-210. DOI: 10.4067/S0718-221X2011000200008

Ghorbani, S., Razavi, R. S., Loghman-Estarki, M. R., and Alhaji, A. (2017). "Synthesis of $\mathrm{MgO}-\mathrm{Y}_{2} \mathrm{O}_{3}$ composite nanopowder with a high specific surface area by the Pechini method," Ceramics International 43(1), 345-354. DOI: 10.1016/j.ceramint.2016.09.162.

Gupta, A., Kumar, A., Sharma, K. V., and Gupta, R. (2018) “Application of high conductive nanoparticles to enhance the thermal and mechanical properties of wood composite," Materials Today: Proceedings 5(1), 3143-3149. DOI:

10.1016/j.matpr.2018.01.121

Kumar, K., Gupta, A., Sharma, K. V., and Nasir, M. (2013). "Use of aluminum oxide nanoparticles in wood composites to enhance the heat transfer during hot-pressing," 
European Journal of Wood and Wood Products 71(2), 193-198. DOI: 10.1007/s00107-013-0664-9

Mantanis, G. I., and Papadopoulos, A. N. (2010) "Reducing the thickness swelling of wood based panels by applying a nanotechnology compound," European Journal of Wood and Wood Products 68(2), 237-239. DOI: 10.1007/s00107-009-0401-6

Nosál, E., and Reinprecht, L. (2017). "Anti-bacterial and anti-mold efficiency of ZnO nanoparticles present in melamine-laminated surfaces of particleboards," BioResources 12(4), 7255-7267. DOI: 10.15376/biores. 12.4.7255-7267

Reinprecht, L., Iždinský, J., and Vidholdová, Z. (2018) "Biological resistance and application properties of particleboards containing nano-zinc oxide," Advances in Materials Science and Engineering 2018, 1-8.

Soltani, M., Najafi, A., Yousefian, S., Naji, H. R., and Bakar, E. S. (2013). "Water repellent effect and dimension stability of beech wood impregnated with nano-zinc oxide," BioResources 8(4), 6280-6287. DOI: 10.15376/biores.8.4.6280-6287

Taghiyari, H. R. (2013). "Effects of nano-silver and nano-zycosil on mechanical strength of heat, vapor, and dry-ice-treated biscuit and dovetail medium-density fiberboard miter joints," Materials and Design 51, 695-700. DOI: 10.1016/j.matdes.2013.04.083

Weichelt, F., Emmler, R., Flyunt, R., Beyer, E., Buchmeiser, M. R., and Beyer, M. (2010). "ZnO-based UV nanocomposites for wood coatings in outdoor applications," Macromolecular Materials and Engineering 295(2), 130-136. DOI:

10.1002/mame.200900135

Article submitted: July 10, 2018; September 9, 2018; Revised version received and accepted: November 29, 2018; Published: January 14, 2019.

DOI: 10.15376/biores.14.1.1618-1625 